\section{A male Reed Warbler and Marsh Warbler hybrid Acrocephalus scirpaceus $\times$ A. palustris in Norway documented with molecular methods}

\author{
Andreas Otterbeck ${ }^{1}$, Svein Dale ${ }^{2}$, \\ Andreas Lindén ${ }^{3} \&$ Gunnhild \\ Marthinsen ${ }^{4}$
}

\begin{abstract}
${ }^{1}$ Marine Biology (MB), Department of Biosciences, University of Oslo, P.O.Box 1066 Blindern, NO-0316 Oslo, Norway; e-mail: andreaot@student.matnat.uio.no;

${ }^{2}$ Department of Ecology and Natural Resource Management, Norwegian University of Life Sciences, P.O. Box 5003, NO-1432 Ås, Norway;

${ }^{3}$ Centre for Ecological and Evolutionary Synthesis (CEES), Department of Biosciences, University of Oslo, P.O. Box 1066 Blindern, NO-0316 Oslo, Norway;

${ }^{4}$ Natural History Museum, University of Oslo, P.O. Box

1172 Blindern, NO-0318 Oslo, Norway
\end{abstract}

\begin{abstract}
We present molecular evidence for a hybrid between Reed Warbler and Marsh Warbler Acrocephalus scirpaceus $\times$ A. palustris from south-eastern Norway. The hybrid was a male and was shown to have a Reed Warbler mother and a Marsh Warbler father. Biometric measurements were intermediate between parent species, and the hybrid sang a mixed song, which in our sample was dominated by Marsh Warbler like sections. The hybrid was only seen sitting in common reed Phragmites australis, and hence, to our knowledge the habitat was more similar to that of Reed Warblers. We propose that documentation of song and habitat of hybrids for which maternal and paternal species are known is valuable for testing hypotheses concerning development of song and habitat selection.
\end{abstract}

\section{INTRODUCTION}

Recent developments in molecular methodology allow confident identification of hybrids as well as the maternal and paternal species in birds (Hebert et al. 2004, Beier et al. 1997, Hansson et al. 2003, Hansson et al. 2004, Lifjeld et al. 2010). This opens new possibilities for assessing hypotheses about the occurrence of hybridization and the development of hybrid characters. In particular, accumulating knowledge of maternal and paternal species of hybrids may shed light on the importance of inheritance versus imprinting and learning on the development of song and habitat selection (Hildén 1965, Cody 1985, Catchpole \& Slater 2008). For example, if hybrids generally choose a habitat which is different from the habitat they were raised in, this might provide evidence for genetic effects on habitat selection overriding effects of imprinting.

Hybridization between Acrocephalus species has been documented for several combinations of species, in many cases with information on maternal and paternal species (Koskimies 1980, 1984, Beier et al. 1997, Hansson et al. 2003, 2004, Lindholm et al. 2007, Lifjeld et al. 2010). In fact, these cases seem to comprise a large proportion of all studies which have identified maternal and paternal species of bird hybrids, and Acrocephalus hybrids may therefore provide a model system for studies of hybrid ecology.

On 23 June 2011, an unidentified Acrocephalus warbler was reported from Østensjøvannet, a wetland nature reserve located in south-east Oslo, Norway $\left(59^{\circ} 53^{`} \mathrm{~N}, 10^{\circ} 49^{\prime} \mathrm{E}\right)$. It was suspected to be a hybrid because it was singing a mixed song with characteristics of both Reed Warbler A. scirpaceus and Marsh Warbler $A$. palustris. To our knowledge, hybrids between these two species have not been documented before using molecular analyses, although such hybrids have been suspected earlier (McCarthy 2006). The aim of this article is to provide molecular evidence for the hybrid status of the bird, to determine its parental species, and to provide a documentation of its song, biometry, and habitat choice. We argue that accumulation of case studies of hybrids will in the future help in testing existing hypotheses for development of characters that may be influenced both by genetics and imprinting or learning.

\section{MATERIAL AND METHODS}

\section{DNA-analyses}

Late evening, on 3 July 2011, the bird was captured in a mistnet within a few minutes, attracted with its own song as playback. It was ringed, measured, photographed and a blood sample was taken.

The molecular analyses of the blood sample were done at The Natural History Museum in Oslo, where also the blood sample is kept, voucher no NHMO-35615. Genomic DNA was extracted using a commercial spin column kit (E.Z.N.A. DNA Kit; Omega Bio-Tek) following the manufacturers' protocol. We sequenced the first part of the mitochondrial cytochrome c oxidase subunit I (COI) gene which is the marker used in DNA barcoding in birds (Kerr et al. 2007). In the Barcode of Life Database (BOLD, Ratnasingham $\&$ Hebert 2007), entries of the two species differ by 
at least $7.8 \%$ uncorrected distance, and this, together with the fact that mitochondrial DNA is inherited maternally, means that we could determine the mother species of the sampled bird by analyzing this marker. The targeted locus was amplified and sequenced with primers PasserF1 and PasserR1 (Lohman et al. 2009). The sequence was submitted to BOLD (BOLD Process ID: BONSC065-13) and GenBank (Accession number $\mathrm{KC} 755399$ ). To determine the paternal species of the sampled bird we analyzed a microsatellite marker that was shown to be monomorphic within and differ between Marsh Warbler and Reed Warbler in Lifjeld et al. (2010); TG02-120 (Dawson et al. 2010).

\section{Song recordings}

On 28 June (evening) and 29 June (morning) AL recorded the song of the bird for in total 6 minutes and 17 seconds. We used a pair of Sennheiser microphones (MKH 70-P48 long shotgun; MKH 30 figure of eight), whose signals were mixed into 2-track stereo wav-files using the MS-technique, on a SoundDevices 702 solid state recorder (sampling rate 48,000; 24-bit precision). The microphones were mounted on a handheld Rycote mount with pistol grip and windshield. We took the recordings from a distance of approximately 7-15 m from the bird. We produced spectrograms in MATLAB (version 7.6.0 R2008a; Natick, Massachusetts: The MathWorks Inc.) based on wav-files that were converted to mono and down-sampled (sampling rate 22,050 and 16-bit precision). Further, we calculated the spectrograms with FFT size 1024, time windows with a width of 882 samples $(0.04 \mathrm{~s})$ weighted with the Blackman-Harris windowing function, and successive windows overlapping with 772 samples. This leads to an approximate temporal resolution of $0.005 \mathrm{~s}$ and frequency resolution of $21.5 \mathrm{~Hz}$.

We identified the most obvious cases of vocal mimicry in the song. Such classification inevitably includes some level of uncertainty, not the least because mimicry does not need to be identical to the original sound, but rather inspired by it. Further, we divided the recording into sections of: 1) typical Reed Warbler song, 2) typical Marsh Warbler song or mimicry of other species (which is common for Marsh Warbler; see Lemaire 1977), 3) sections difficult to classify, e.g., with traits of both species. This approach is similar to that of
Lemaire (1977), with the exception that he classified all song sections into categories 1 or 2 . Our identification of mimicked sounds and the classification of sections were done subjectively, based on solid experience on the song of the parental species and the vocalizations of European bird species.

The numbers of sections (Reed Warbler vs. Marsh Warbler) were compared with a binomial test (with a null hypothesis of binomial probability 0.5 ) and the average (log-transformed) section lengths with a two sample t-test. We further formed a Marsh Warbler to Reed Warbler-ratio using the total time classified to the respective species. This can be seen as a way to quantify the influence of each parental species on the song, despite some obvious limitations. We used a bootstrap approach to investigate the uncertainty associated with this ratio, by resampling with replacement all the sections 10,000 times.

\section{Habitat}

The habitat of the territory of the hybrid was described qualitatively by identifying the major plant species present. The habitat of the hybrid was compared to habitats of Reed Warblers and Marsh Warblers in Oslo county and neighbouring Akershus county recorded by SD during extensive field work during 1995-2012, which resulted in information about species occurrence at about 2000 sites. The comparisons focused on the presence/absence of common reed Phragmites australis at the sites where Reed Warblers or Marsh Warblers had been recorded during the breeding season because Gjershaug et al. (1994) reported that Reed Warblers in Norway breed mainly in reed beds whereas Marsh Warblers prefer areas with bushes and tall herbs.

\section{RESULTS}

DNA barcoding revealed that the mother of the assumed hybrid was a Reed Warbler, as the sequenced marker matched individuals of this species in BOLD with $98.8 \%-100 \%$. Analysis of the microsatellite locus revealed one allele specific for Marsh Warbler (allele size $231 \mathrm{bp}$ ) and one specific for Reed Warbler (233 bp). The bird was thus confirmed to be a hybrid between Marsh Warbler and Reed Warbler.

Table 1. Biometry of the hybrid between Reed Warbler and Marsh Warbler Acrocephalus scirpaceus $\times$ A. palustris from Lake Østensjøvannet in Oslo, south-eastern Norway, compared to range values for parental species given by Svensson (1992).

\begin{tabular}{lccc}
\hline Character & Hybrid & Reed Warbler & Marsh Warbler \\
\hline Wing length (mm) & 70 & $62-73$ & $68-76$ \\
Notch on 2nd primary (mm) & 11.8 & $11-15$ & $8.5-12$ \\
Notch/wing ratio & 0.169 & $0.167-0.231$ & $0.125-0.160$ \\
\hline
\end{tabular}




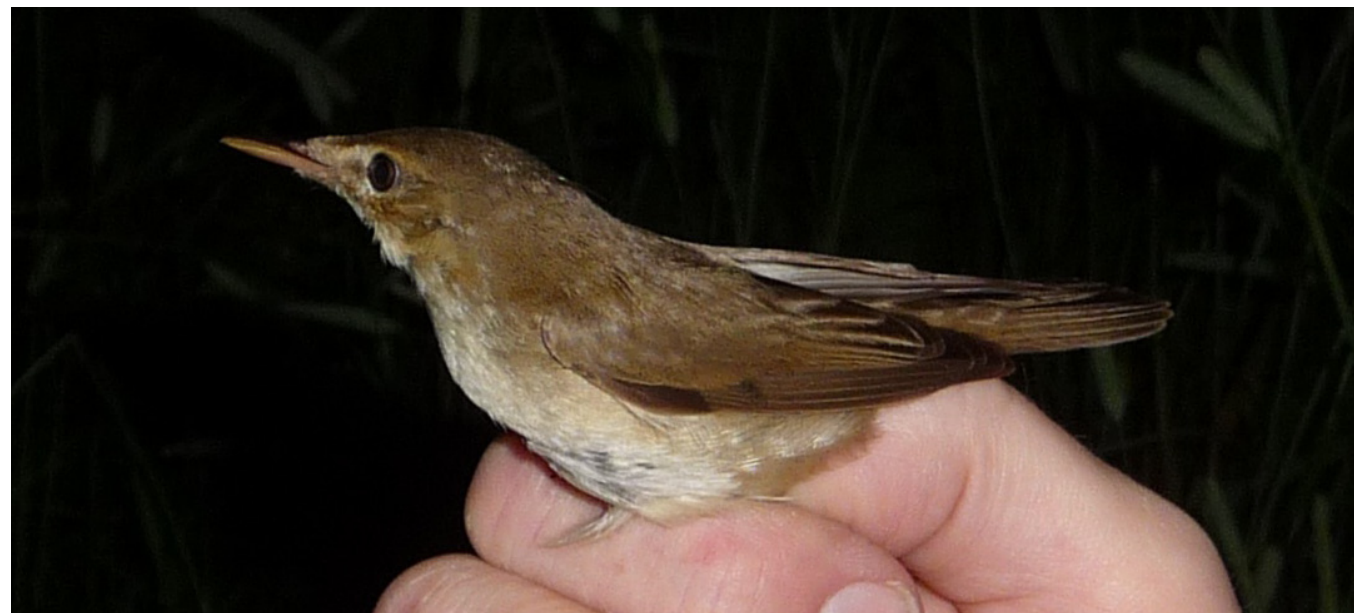

Figure 1. The hybrid between Reed Warbler and Marsh Warbler Acrocephalus scirpaceus $\times$ A. palustris, captured on 3 July 2011 at Østensjøvannet in Norway.

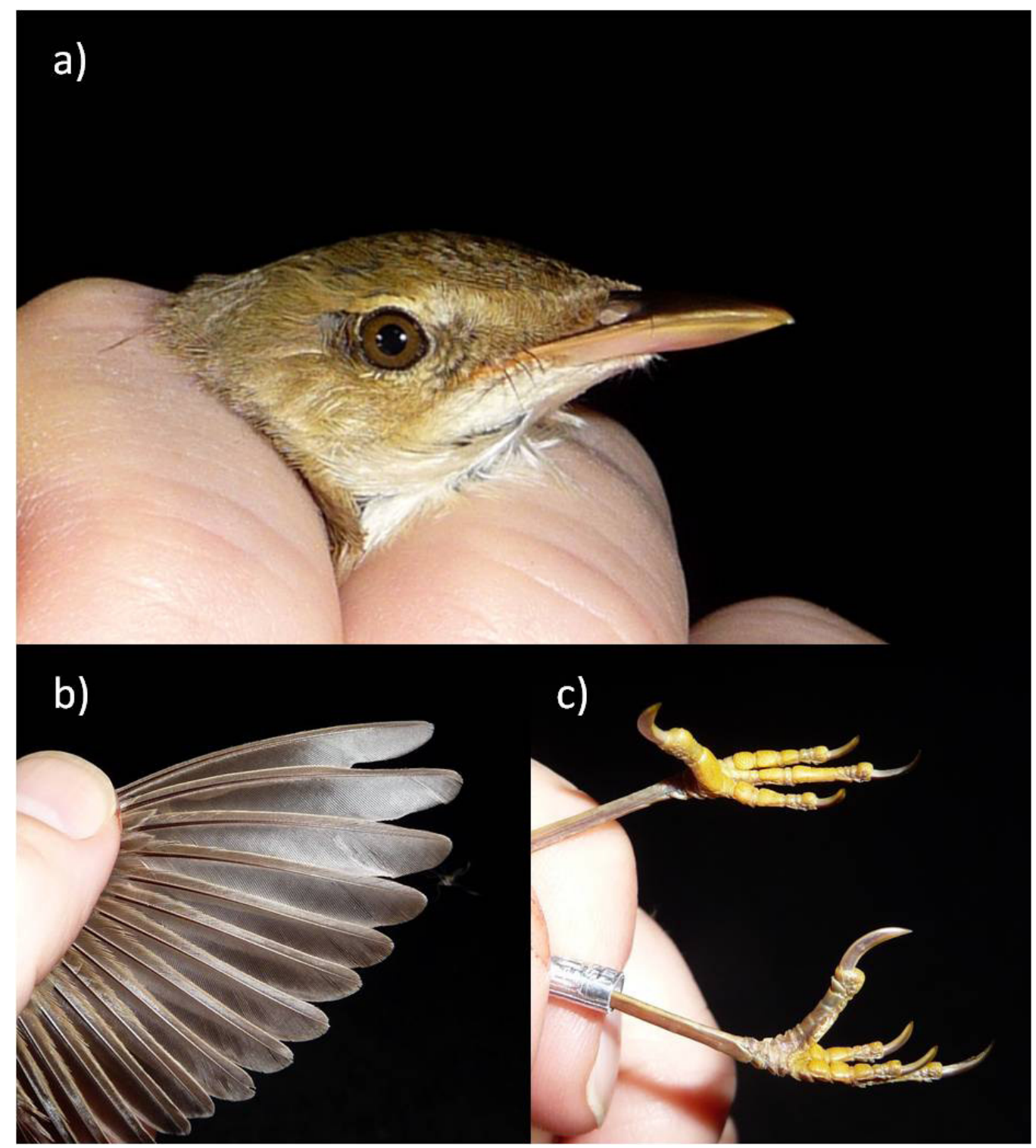

Figure 2. The hybrid showed: a) Marsh Warbler-like head, with a short and heavy bill, and a somewhat diffuse and incomplete eyering, b) wing with a long innerweb notch on the 2nd outermost primary as typical for Reed Warbler, and c) Marsh Warbler-like feet, with pale reddish toned tarsi, straw yellow feet, pale claws, and a relatively thick and short hind claw. 
Table 2. List of subjectively identified sounds mimicked by the hybrid in the recording made on 29 May. All identified mimicry on 28 May reoccurred in the latter (longer) recording. The column 'Time' refers to the location (M.SS) in the analysed sound file. The list is not exhaustive and hence the species identified should be viewed merely as examples of mimicry.

\begin{tabular}{|c|c|c|}
\hline Time & Species & Type of sound \\
\hline 0.20 & Barn Swallow Hirundo rustica & alarm call \\
\hline 0.25 & White Wagtail Motacilla alba & flight call \\
\hline 0.36 & Song Thrush Turdus philomelos & warning call \\
\hline 0.41 & Great Tit Parus major & calls \\
\hline 0.46 & White Wagtail & song \\
\hline 0.56 & Barn Swallow & flight call \\
\hline 1.25 & Great Tit/Marsh Tit Parus major/Poecile palustris & call \\
\hline 1.37 & Icterine Warbler Hippolais icterina & song \\
\hline 2.01 & Goldfinch Carduelis carduelis & call \\
\hline 2.23 & Unidentified Bunting Emberiza sp. & call \\
\hline 2.32 & Common Tern Sterna hirundo & call \\
\hline 2.41 & Unidentified Sparrow Passer sp. & calls \\
\hline 2.48 & Greenfinch Carduelis chloris & flight call \\
\hline 3.07 & Blue Tit Cyanistes caeruleus & call \\
\hline 3.09 & Barn Swallow & call \\
\hline 3.21 & Greenfinch & flight call \\
\hline 3.39 & Common Tern & call \\
\hline 4.09 & Chaffinch Fringilla coelebs & call \\
\hline 4.10 & Blue Tit & call \\
\hline 4.24 & Redwing Turdus iliacus & call \\
\hline 4.27 & House Sparrow Passer domesticus & call \\
\hline 4.29 & House Martin Delichon urbicum & call \\
\hline 4.41 & Common Tern Sterna hirundo & call \\
\hline 4.46 & Sedge Warbler Acrocephalus schoenobaenus & song \\
\hline 4.58 & Unidentified Sparrow Passer sp. & calls \\
\hline 5.00 & Redstart Phoenicurus phoenicurus & call \\
\hline
\end{tabular}

In contrast to hybrids between warblers with distinct plumage characters (see Lifjeld et al. 2010) the Marsh Warbler and Reed Warbler are very similar in visual appearance. This makes the recognition of phenotypic hybrid traits difficult to judge by the observers in the field. The basic biometric measurements were intermediate between Reed Warbler and Marsh Warbler, and were in the region where the measurements overlap between the two species. The composite measure wing/ notch ratio was also intermediate, but if hybridization was not considered as an option, the bird could according to Svensson (1992) have been taken for a Reed Warbler (Table 1). The bill was short and thick, i.e., shaped similarly to that of Marsh Warbler, and also the colouration of tarsi, feet and claws were somewhat closer to Marsh Warbler (Figures 1 and 2).

The song of the hybrid resembled that of Marsh Warbler, with e.g. frequent mimicry of other bird species, highly variable rhythm, both high- and low pitched, harmonic and harsh sounds, often presented in complicated bursts with rapidly alternating elements. Despite these characters, typical for the Marsh Warbler, the bird regularly inserted both short and longer sections of typical Reed Warbler song. Apart from the song of parental species we could identify mimicry of 16 other bird species or genera (Table 2). The list is most likely incomplete, as the bird may have mimicked more exotic species from the wintering grounds, which we are not able to identify (possibly some of the 'typical Marsh Warbler sounds'). Figure 3 shows the spectrogram of a 25 second sample of mixed song with shorter insertions of Reed Warbler's song. In Figure 4, spectrograms for a Marsh Warbler-like and a Reed Warbler-like section are compared to spectrograms of the parental species, recorded by AL in the same area (Oslo-Akershus) and season (late June 2011), using the same equipment.

The recordings of the hybrid consisted of in total 5 minutes of active song, which we classified into 71 sections, assigned to either parental species or the unidentified category (see summary in Table 3 ). The hybrid sang Marsh Warbler-like song for 58\% of the time and Reed Warbler-like song for only $21 \%$ of the time. This resulted in an estimated Marsh Warbler to Reed Warbler ratio of $2.71(95 \% \mathrm{CI}=\{1.43,5.42\})$. The null hypothesis of a unit ratio could be rejected with a two tailed test (based on the bootstrap, $p=0.002$ ). A slightly larger number of sections were assigned to Marsh Warbler compared to Reed Warbler, but the 


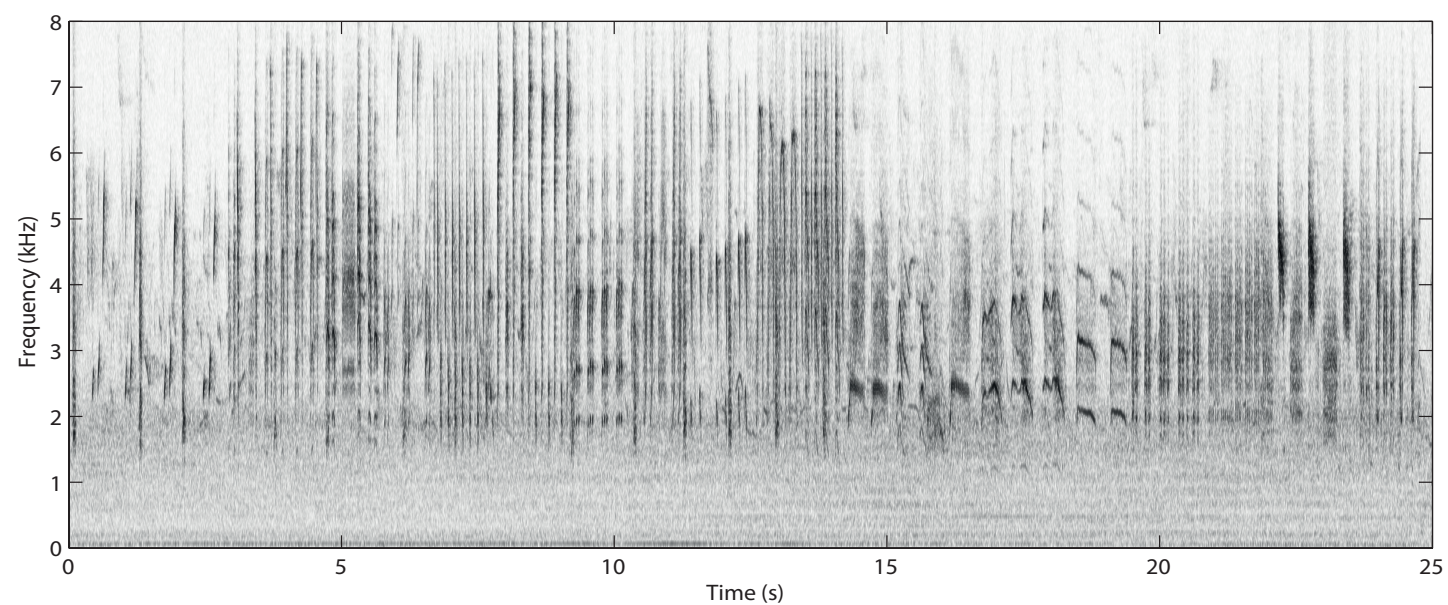

Figure 3. Spectrogram of the hybrid song, for a 25-second section of mixed song, resembling most the song of Marsh Warbler, but including shorter periods of Reed Warbler song. The $\mathrm{x}$-axis represents time in seconds, the $\mathrm{y}$-axis frequency (pitch) in kilohertz, and the colour the relative amplitude in decibel (from white, via grey to black). Preferably, listen to the sound file associated while looking at this figure (Supplementary file 1).

difference was not statistically significant (binomial test, two tailed, $\mathrm{n}=34+21, \mathrm{p}=0.058)$. However, the average duration was significantly longer in the sections assigned to Marsh Warbler (time in seconds: $5.16 \pm 3.88 \mathrm{SD})$ compared to Reed Warbler $(3.08 \pm 1.86$ $\mathrm{SD})$, based on a two-tailed two sample t-test done on the logarithmic scale $(\mathrm{t}=2.57, \mathrm{df}=53, \mathrm{p}=0.013)$. For the unclassified sections $(\mathrm{n}=16)$ the average duration was $4.29 \pm 3.21 \mathrm{SD}$.
The hybrid individual was located in the north end of the lake, and was observed within a patch strongly dominated by common reed and surrounded on the northern edge by bushes and small trees (Salix spp., Rosa sp., Sambucus racemosa, Betula pendula, Alnus glutinosa), grasses (e.g., Dactylis glomerata, Alopecurus pratensis, Phleum pratense, Elytrigia repens) and herbs (e.g., Filipendula ulmaria, Lysimachia vulgaris, Epilobium angustifolium,
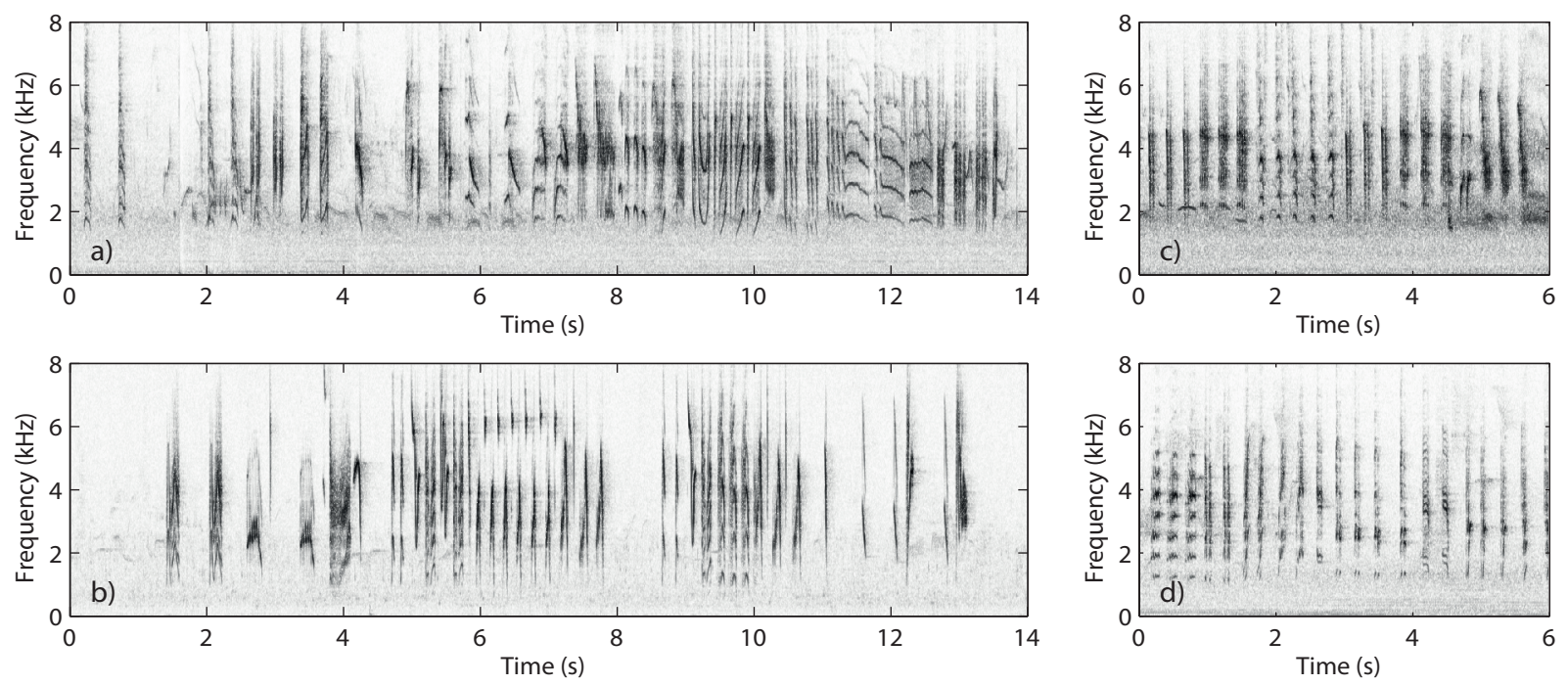

Figure 4. Comparison of spectrograms between sections of the hybrid song that resemble the parental species, and corresponding genuine representatives of Marsh Warbler (Sørkedalen, Oslo, 23 June 2011) and Reed Warbler (Dælivannet, Bærum, 30 June 2011). In the comparison between the hybrid (a) and Marsh Warbler (b), pay attention to the variable rhythm, with fast and complicated sequences of diverse types of elements, with highly variable pitches. In the comparison between the hybrid (c) and Reed Warbler (d), notice a fairly constant rhythm, with (often pair-wise) repeated harsh elements (energy evenly distributed over several frequencies). Preferably listen to the sound files associated while comparing the figures (Supplementary file 2). 


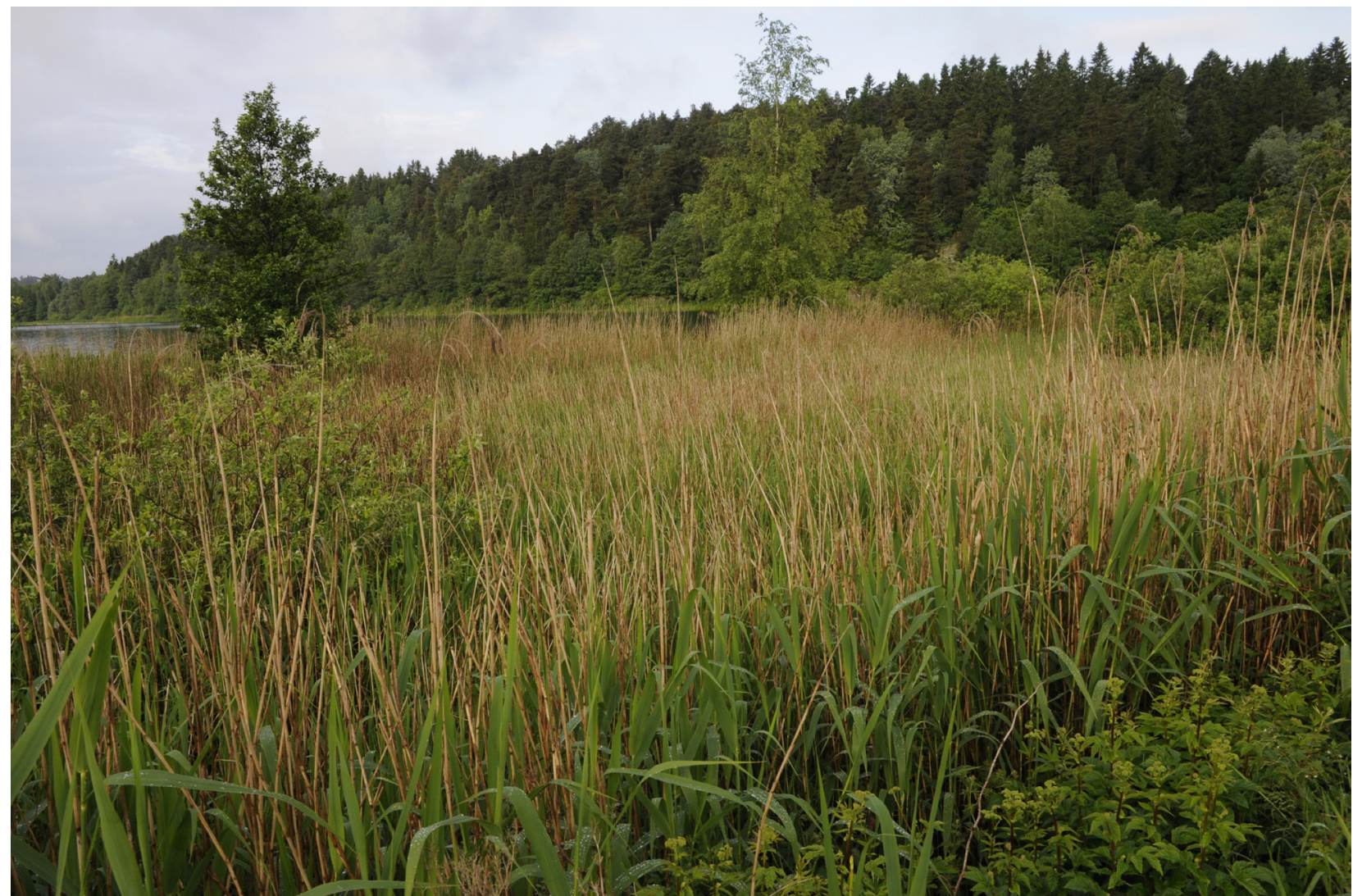

Figure 5. Photograph of the habitat where the hybrid was singing at Lake Østensjøvannet in Oslo, south-eastern Norway.

Cirsium arvense, Rubus idaeus, Urtica dioica, Vicia sepium) (Figure 5). In comparison, reed is the dominant plant species in all 41 known sites with breeding Reed Warblers in the counties of Oslo and Akershus. On the other hand, common reed does not occur at all in 110 of 147 Marsh Warbler sites. In these sites Marsh Warblers mainly use areas with tall herbs and low bushes. In the remaining 37 sites where common reed occurs, the Marsh Warblers usually sing perched on tall herbs and small bushes (seldom on the reeds). All four times seen, the hybrid bird was singing perched on the reeds. While this choice of singing post does not exclude Marsh Warbler, it is considered far more typical for the Reed Warbler.

\section{DISCUSSION}

Using molecular evidence we were able to confirm the hybrid status of our individual, having a Marsh Warbler father and a Reed Warbler mother, and to our knowledge this represents the first documented hybrid between these two species. Our conclusion of maternal and paternal species assumes that there is no paternal mitochondrial leakage. This phenomenon occurs in e.g., Drosophila and mice, but has been reported for one bird species only (Kvist et al. 2003). We consider this scenario unlikely.
It has been proposed that hybrid mating occurs more often between the females of a rare species and the males of a common species (Wirtz 1999), but for birds Randler (2002) showed that this was not the case, and he suggested that more frequent hybridization occurred when one species had a scarcity of conspecifics, no matter the sex of the rare species. Lifjeld et al. (2010) documented a case in which the mother of an Acrocephalus hybrid was of the rarer species. However, Hansson et al. (2003) documented hybridization in an area in which both parental species were common. In our case, we do not know the origin of the hybrid, and even if it had been born locally, so it is somewhat unclear which species was the rarer one. Until the 1990s, the Reed Warbler was much more common than the Marsh Warbler in Oslo and Akershus, including this specific site (Dale et al. 2001), but the Marsh Warbler has shown a rapid increase from around 2000 in southeastern Norway and is now roughly equally abundant (see e.g., Gylseth 2009).

Hybrid Acrocephalus have been shown to sing mixed song (Lindholm et al. 2007), or mixed song but predominantly from the mother species (Beier et al. 1997, Lifjeld et al. 2010). Because territories are generally established by male birds, hybrids are most likely to be imprinted on their father species, so the latter cases with a predominance of song from the mother species argue for a dominant role of 
inheritance on song development (if hybrids result from mixed pairs rather than extra-pair copulations). Lemaire (1977) reported three cases of Reed Warblers singing mixed song of Reed Warbler and Marsh Warbler, suggesting that mixed song is not a character exclusive for hybrids. However, these individuals did not undergo any molecular investigation, and were identified using standard characters such as biometric measures, plumage, body shape and bill length. While the biometry and plumage of Lemaire's three mixed singers clearly pointed at Reed Warbler with more typical biometric measurements than our hybrid, it is not completely ruled out that some of them were hybrids. The variation in hybrids is unknown. Lemaire (1977) observed that one of the male Reed Warblers with mixed song 'paired successfully' with a female Marsh Warbler, which provides evidence of crossmating between the two species.

Our hybrid sang a mixed song with the paternal species (Marsh Warbler) represented 2.71 times more than the song of the maternal species ( $\min 1.43$, max 5.42). This result is similar to that of Lemaire (1977) in his analysis of genuine Reed Warblers singing mixed song. The null hypothesis of equal time allocation for both parental species' song might be a bit artificial, as we assigned typical mimicry to Marsh Warbler sections and as Marsh Warbler song naturally contains longer pauses in the song. Nevertheless, this method can be a useful way to quantitatively describe mixed song, and especially to compare several individuals with the same parental species. A drawback is that the subjective classification might lead to observer bias in the data, which in meta-analyses would take the form of statistical noise. Observer bias and resulting noise can potentially be reduced by letting several people analyse each case and report the average outcome. Alternatively, the noise can be reduced by letting the same person analyse all data and hence using a fixed level of observer bias.

Few reports on the habitat selection of hybrids with known maternal and paternal species have been published. Joseph \& Moritz (1993) found that a hybrid Sericornis in Australia was collected in the habitat of the paternal species, although the individual was probably not a first generation hybrid. For Acrocephalus, Lindholm et al. (2007) reported that the habitat of a hybrid was typical of both parent species, whereas Lifjeld et al. (2010) apparently recorded the hybrid in the habitat of the father species. In our case, the habitat of the hybrid was most similar to that of the mother species (Reed Warbler) because it was dominated by reeds. Thus, evidence to date is scarce and does not indicate a consistent pattern regarding the habitat selection of hybrids in relation to that of parental species.

We argue that data on song and habitat selection should be recorded and published for all hybrids that have also been documented by molecular methods, with maternal and paternal species determined. Such data will build a better basis for evaluation of the relative role of inheritance and imprinting or learning, complementing studies using interspecific crossfostering (Slagsvold et al. 2002, Eriksen et al. 2009). Currently, journals generally have a more restrictive attitude towards publishing case studies than before, in particular if similar case studies have already been published. While this is in many aspects understandable, we argue that there is a clear need for searchable fora with citable short reports (e.g., online data bases). These kinds of data, which cannot be collected on purpose by individual researchers, will over time accumulate into a valuable source of data for formal testing of existing hypotheses.

Acknowledgements. We thank Carsten Lome for help in catching the bird, taking blood samples and measuring biometry. Petteri Lehikoinen, William Velmala and Aleksi Lehikoinen provided useful comments about the photographs. Thanks to Aubrey Roberts for helpful comments regarding the language in our final manuscript. AL was funded by the EU, through a Marie Curie Intra-European Fellowship (ref. PIEF-GA-2010-273986).

\section{REFERENCES}

Beier, J., Leisler, B. \& Wink, M. 1997. Ein Drossel- x Teichrohrsänger-Hybride Acrocephalus arundinaceus $\mathrm{x}$ A. scirpaceus und der Nachweis seiner Elternschaft. Journal für Ornithologie 138: 51-60.

Catchpole, C.K. \& Slater, P.J.B. 2008. Bird song: biological themes and variations. Cambridge University Press, Cambridge.

Cody, M.L. (ed.). 1985. Habitat selection in birds. Academic Press, Orlando.

Dale, S., Andersen, G.S., Eie, K., Bergan, M. \& Stensland, P. 2001. Guide til fuglelivet i Oslo og Akershus. Norsk Ornitologisk Forening, avdeling Oslo og Akershus.

Dawson, D., Horsburgh, G.J., Küpper, C., Stewart I.R.K., Ball, A.D., Durrant, K.L., Hansson, B., Bacon, I., Bird, S., Klein, Á., Krupa, A.P., Lee, J.-W., Martín-Gálvez, D., Simeoni, M., Smith, G., Spurgin, L.G. \& Bruke, T. 2010. New methods to identify conserved microsatellite loci and develop primer sets of high cross-species utility - as demonstrated for birds. Molecular Ecology Resources 10: 475-494.

Eriksen, A., Lampe, H.M. \& Slagsvold, T. 2009. Interspecific cross-fostering affects song acquisition but not mate choice in Pied Flycatchers, Ficedula hypoleuca. Animal Behaviour 78: 857-863.

Gjershaug, J.O., Thingstad, P.G., Eldøy, S. \& Byrkjeland, S. (eds.). 1994. Norsk fugleatlas. Norsk Ornitologisk Forening, Klæbu, Norway.

Gylseth, P. 2009. Rapport fra LRSK for Oslo og Akershus for 2008. Toppdykker’n 32 supplement: 1-43.

Hansson, B., Gavrilov, E. \& Gavrilov, A. 2003. Hybridisation between Great Reed Warblers Acrocephalus arundinaceus and Clamorous Reed Warblers $A$. 
stentoreus: morphological and molecular evidence. Avian Science 3: 145-151.

Hansson, B., Roggeman, W. \& De Smet, G. 2004. Molecular evidence of a Reed Warbeler x Great Reed Warbler hybrid (Acrocephalus scirpaceus x A. arundinaceus) in Belgium. Journal of Ornithology 145: 159-160.

Hebert, P.D.N., Stoeckle, M.Y., Zemlak, T.S. and Francis, C.M.. 2004. Identification of birds through DNA barcodes. Public Library of Science Biology 2: 16571663.

Hildén, O. 1965. Habitat selection in birds. Annales Zoologici Fennici 2: 53-75.

Joseph, L. \& Moritz, C. 1993. Hybridization between the white-browed and Atherton Scrubwrens - detection with mitochondrial-DNA. Emu 93: 93-99.

Kerr, K.C.R., Stoeckle, M.Y., Dove, C.J., Weigt, L.A., Francis, C.M. \& Hebert, P.D.N. 2007. Comprehensive DNA barcode coverage of North American birds. Molecular Ecology Notes 7: 535-543.

Koskimies, P. 1980. Breeding biology of Blyth's Reed Warbler Acrocephalus dumetorum in SE Finland. Ornis Fennica 57: 26-32.

Koskimies, P. 1984. Polygyny in Blyth's Reed Warbler Acrocephalus dumetorum. Annales Zoologici Fennici 21: 239-242.

Kvist, L., Martens, J., Nazarenko, A. A., Orell, M. (2003) Paternal leakage of mitochondrial DNA in the Great Tit (Parus major). Mol. Biol. Evol. 20: 243-247.

Lemaire, F. 1977. Mixed song, Interspecific competition and hybridization in the Reed and Marsh Warblers (Acrocephalus scirpaceus and palustris). Behaviour 63: 215-240.
Lifjeld, J.T., Marthinsen, G., Myklebust, M., Dawson, D.A \& Johnsen, A. 2010. A wild Marsh Warbler x Sedge Warbler hybrid (Acrocephalus palustris x A. schoenobaenus) in Norway documented with molecular markers. Journal of Ornithology 151: 513-517.

Lindholm, A., Bensch, S., Dowsett-Lemaire, F., Forsten, A. \& Kärkkäinen, H. 2007. Hybrid Marsh x Blyth's Reed Warbler with mixed song in Finland in June 2003. Dutch Birding 29: 223-231.

Lohman, D.J., Prawiradilaga, D.M. \& Meier, R. 2009. Improved COI barcoding primers for Southeast Asian perching birds (Aves: Passeriformes). Molecular Ecology Resources 9: 37-40.

McCarthy, E. 2006. Handbook of avian hybrids of the world. Oxford University Press, Oxford.

Randler, C. 2002. Avian hybridization, mixed pairing and female choice. Animal Behaviour 63: 103-119.

Ratnasingham, S. \& Hebert, P.D.N. 2007. BOLD: The Barcode of Life data system (www.barcodingoflife. org). Molecular Ecology Notes 7: 355-364.

Slagsvold, T., Hansen, B.T., Johannessen, L.E. \& Lifjeld, J.T. 2002. Mate choice and imprinting in birds studied by cross-fostering in the wild. Proceedings of the Royal Society B 269: 1449-1455.

Svensson, L. 1992. Identification guide to European passerines. Fourth edition, Stockholm.

Wirtz, P. 1999. Mother species-father species: unidirectional hybridization in animals with female choice. Animal Behaviour 58: 1-12.

Received 18 March 2013. Accepted 21 May 2013.

SUPPLEMENTARY FILE 1:

https://boap.uib.no/index.php/ornis/article/view/351/429

SuPPLEMENTARY FILE 2 :

https://boap.uib.no/index.php/ornis/article/view/351/430 